\title{
Insights into genomics of salt stress response in rice
}

Kundan Kumar ${ }^{1 *}$, Manu Kumar ${ }^{2}$, Seong-Ryong Kim² ${ }^{2 *}$, Hojin Ryu ${ }^{3}$ and Yong-Gu Cho ${ }^{4^{*}}$

\begin{abstract}
Plants, as sessile organisms experience various abiotic stresses, which pose serious threat to crop production. Plants adapt to environmental stress by modulating their growth and development along with the various physiological and biochemical changes. This phenotypic plasticity is driven by the activation of specific genes encoding signal transduction, transcriptional regulation, ion transporters and metabolic pathways. Rice is an important staple food crop of nearly half of the world population and is well known to be a salt sensitive crop. The completion and enhanced annotations of rice genome sequence has provided the opportunity to study functional genomics of rice. Functional genomics aids in understanding the molecular and physiological basis to improve the salinity tolerance for sustainable rice production. Salt tolerant transgenic rice plants have been produced by incorporating various genes into rice. In this review we present the findings and investigations in the field of rice functional genomics that includes supporting genes and networks (ABA dependent and independent), osmoprotectants (proline, glycine betaine, trehalose, myo-inositol, and fructans), signaling molecules $\left(\mathrm{Ca}^{2+}{ }^{2}\right.$ abscisic acid, jasmonic acid, brassinosteroids) and transporters, regulating salt stress response in rice.
\end{abstract}

Keywords: Rice; Salt stress; Osmoprotectants; Signaling molecules; Transporters

\section{Introduction}

World agriculture faces a challenging task to produce $70 \%$ more food for an additional 2.3 billion people by 2050 (FAO 2009). The lower agriculture crop productivity is mostly attributed to various abiotic stresses, which is a major area of concern to cope with the increasing food requirements (Shanker and Venkateswarlu 2011). The major abiotic stresses includes high salinity, drought, cold, and heat negatively influence the survival, biomass production and yield of staple food crops which is a major threat to food security worldwide (Thakur et al. 2010; Mantri et al. 2012).

Among abiotic stresses, soil salinity is one of the most brutal environmental factors and a complex phenotypic and physiological phenomenon in plants imposing ion imbalance or disequilibrium, hyperionic and hyperosmotic stress, disrupting the overall metabolic activities and thus

\footnotetext{
* Correspondence: kundan@goa.bits-pilani.ac.in; sungkim@sogang.ac.kr; ygcho@chungbuk.ac.kr

${ }^{1}$ Department of Biological Sciences, Birla Institute of Technology \& Science, K. K. Birla Goa Campus, Goa 403726, India

${ }^{2}$ Department of Life Science, Sogang University, Seoul 121-742, Korea

${ }^{4}$ Department of Crop Science, Chungbuk National University, Cheongju 361-763, Korea

Full list of author information is available at the end of the article
}

limiting the productivity of crop plants worldwide (Munns and Tester 2008). Worldwide more than 80 million hectares of irrigated land (representing $40 \%$ of total irrigated land) have already been damaged by salt (Xiong and Zhu 2001). Salt stress leads to severe inhibition of plant growth and development, membrane damages, ion imbalances due to $\mathrm{Na}^{+}$and $\mathrm{Cl}^{-}$accumulation, enhanced lipid peroxidation and increased production of reactive oxygen species like superoxide radicals, hydrogen peroxide and hydroxyl radicals. Area under salt stress is increasing due to many factors including climate change, rise in sea levels, excessive irrigation without proper drainage in inlands and underlying rocks rich in harmful salts etc. It is estimated that if current scenario of salinity stress would persist, there may be loss of $50 \%$ of present cultivated land for agriculture by 2050 (Wang et al. 2003).

Rice (Oryza sativa L.) is the world's most important food crop and a primary source of food for more than half of the population. More than 90 per cent of the world's rice is grown and consumed in Asia, where 60 percent of the earth's people live. Salinity is the most common abiotic stress encountered by rice plants and classified as a salt sensitive crop in their early seedling stages (Lutts et al. 1995)

\section{实}


and limit its productivity (Todaka et al. 2012). To improve the yield under salt stress condition, it is essential to understand the fundamental molecular mechanisms behind stress tolerance in plants. Salinity stress tolerance is a quantitative trait which is controlled by multiple genes (Chinnusamy et al. 2005). During the last two decades, number of genes conferring salt stress tolerance in plants have been isolated and they are involved in signal transduction and transcription regulation (Chinnusamy et al. 2006; Kumari et al. 2009), ion transporters (Verma et al. 2007; Singh et al. 2008; Uddin et al. 2008) and metabolic pathways (Sakamoto et al. 1998; Singla-Pareek et al. 2008). In the current review we try to focus on the salt responsive genes and genome networks, signal transduction, osmoprotectants and ion transporters involved in salinity stress response in rice.

\section{Review}

Salt stress tolerance-supportive genes and pathways in rice Salt stress evokes both osmotic stress and ionic stress which inhibits the plant's normal cell growth and division. To encounter the adverse environment, plants maintain osmotic and ion homeostasis with rapid osmotic and ionic signaling (Figure 1). Osmotic stress due to high salt rapidly increases abscisic acid (ABA) biosynthesis, thus regulating ABAdependent stress response pathway. There are several salt stress inducible genes which are ABA-independent (Figure 2).

\section{Salt stress tolerance via ABA-dependent pathway}

High salinity-induced osmotic stress increases the biosynthesis of ABA. ABA biosynthesis via terpenoid pathway starting from isopentenyl pyrophosphate (IPP) has been reviewed in rice (Ye et al. 2012). Among many genes involved in this pathway, a phytoene synthase gene, OsPSY3 and 9-cis-epoxycarotenoid dioxygenases genes (OsNCED3, OsNCED4 and OsNCED5) are induced one hour after salt stress and their expression is well correlated to the level of $\mathrm{ABA}$ in rice roots (Welsch et al. 2008). ABA then acts as a regulator initiating second round of signaling salt stress response in ABA-dependent pathway. Here we reviewed genes for protein kinases (Receptor-like kinases, $R L K S$; Mitogen activated protein kinases, MAPKs; SNF1-related protein kinases, $S n R K s ; \mathrm{Ca}^{2+}$ dependent protein kinases, $C D P K s$ ), transcription factors (TFs), micro RNAs and reactive oxygen species (ROS) involved in the salt stress tolerance through ABA-dependent pathway (Figure 2).

In plant, protein kinases play important roles in regulating the stress signal transduction pathways. Receptor-like kinases (RLKs) have important roles in plant growth, development and stress responses. Salt, drought, $\mathrm{H}_{2} \mathrm{O}_{2}$ and ABA treatments induced the expression of a putative RLK gene, OsSIK1. Transgenic rice plants overexpressing OsSIK1 (OsSIK1-ox) show higher tolerance to salt and drought stresses than control plants and the knockout mutants sik1 as well as RNA interference (RNAi) plants (Ouyang et al. 2010). Mitogen activated protein (MAP) kinase cascades play a crucial role in salt stress response in rice as well. Until now, at least two salt inducible MEKKs have been reported in rice. One of them is OsEDR1 which is upregulated by various environmental stresses such as high salt, physical cutting and hydrogen peroxide (Kim et al. 2003). A putative MEKK mutant, dsm1, showed sensitivity to salt stress as well as drought stress than wild type plants (Ning et al. 2010). Although these genes are responsive to salt stress, there is no

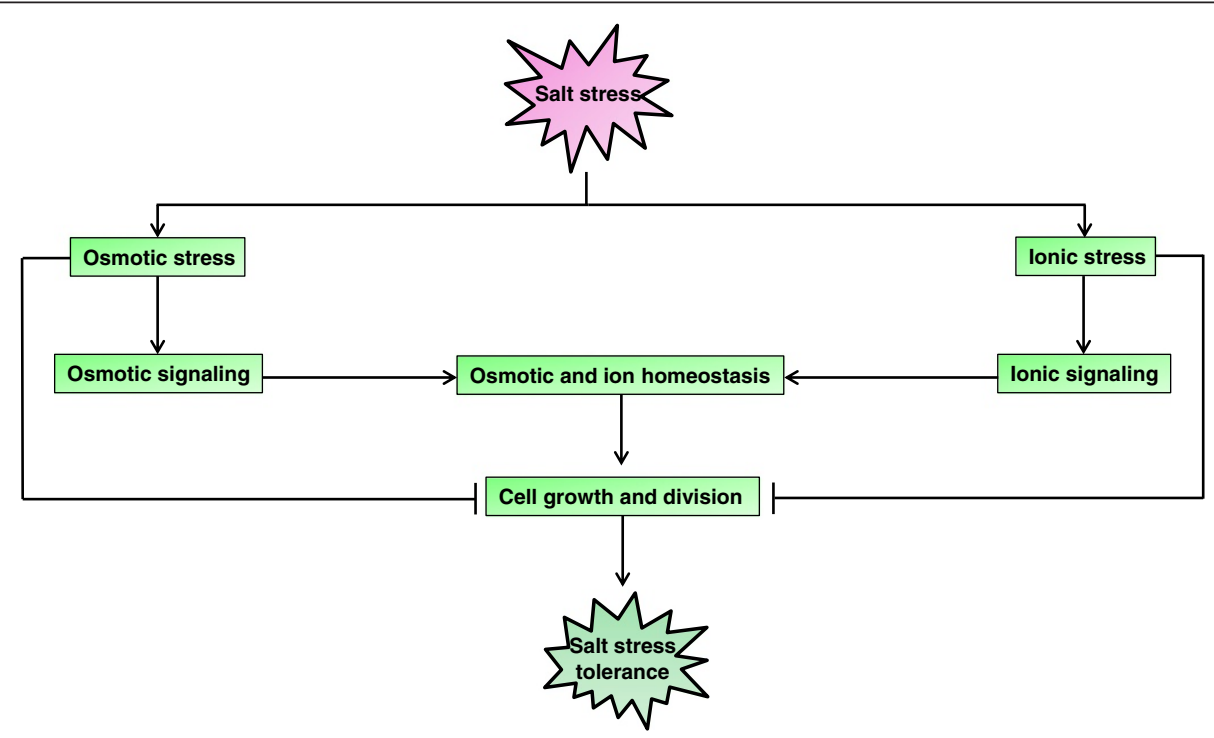

Figure 1 Diagrammatic representation of salt stress response in rice. Growth and division of the cell under salt stress depends on osmotic and ionic signaling. 


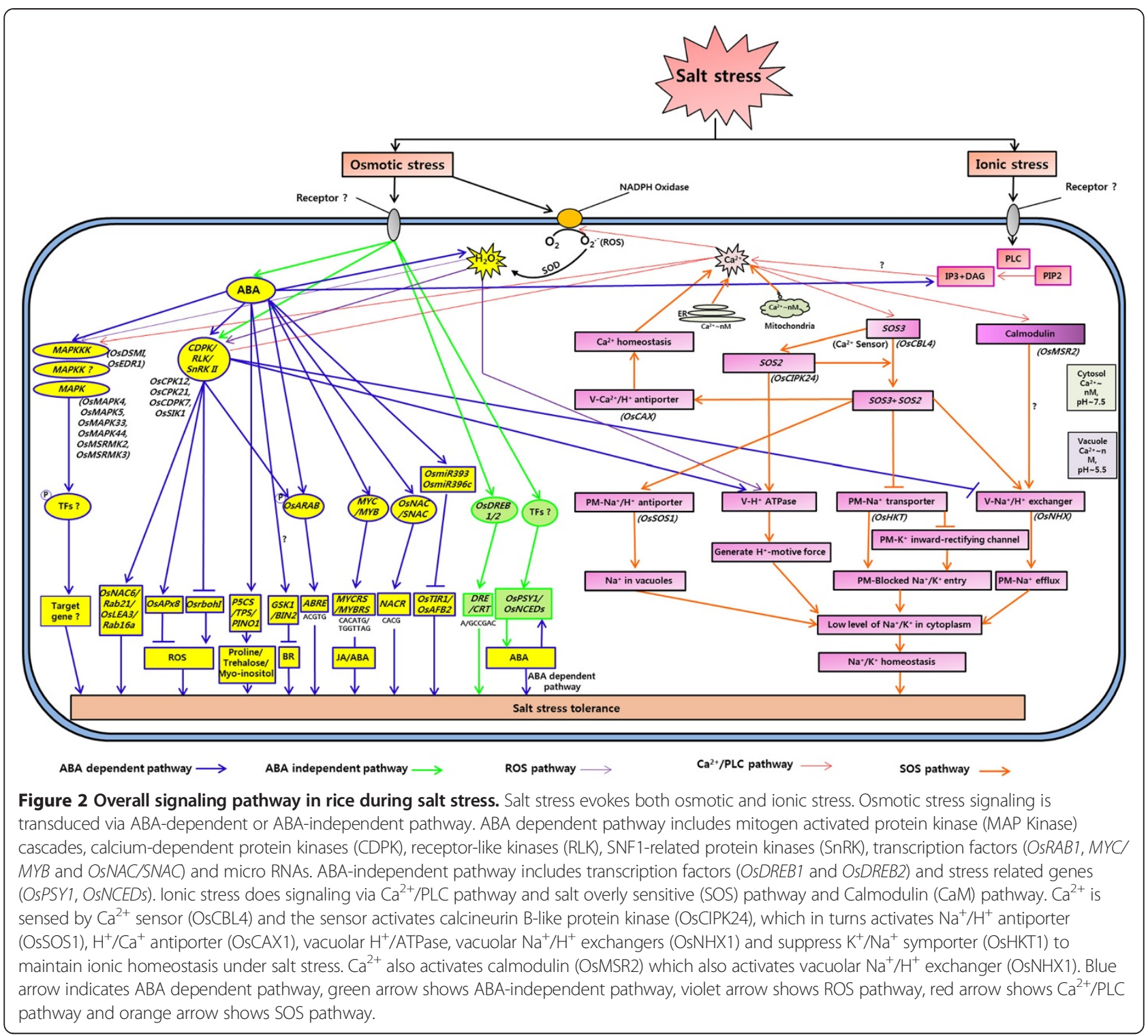

evidence that the MEKKs are regulating any downstream MKK. Several salt-inducible MAPKs have been reported in rice. Transcriptional regulation of OsMAPK4 by salt, cold and sugar starvation was reported although its ABA-dependency is not clear (Fu et al. 2002). Biotic and abiotic stress inducible OsMAPK5 has been cloned and overexpressed in rice which subsequently exhibited increased tolerance to salt, drought and cold stresses with increased kinase activity (Xiong et al. 2003). Expression of two novel MAPKs, OsMSRMK2 and OsMSRMK3 were induced by various environmental stresses suggesting their possible involvement in defense/stress response pathways (Agrawal et al. 2002, 2003). A putative salt and ABA-inducible MAPK gene was introduced into transgenic rice and the plants exhibited higher $\mathrm{Na}^{+} / \mathrm{K}^{+}$ratio than OsMAPK44 suppressed plants under salt stress indicating that OsMAPK44 may have a role in ion balance during salt stressed condition (Jeong et al. 2006). Overexpression of a drought stress inducible OsMAPK33 in transgenic rice also revealed a result similar to that of OsMAPK44 showing higher $\mathrm{Na}^{+} / \mathrm{K}^{+}$ ratio than wild type plants indicating the negative role of OsMAPK33 in salt stress tolerance through unfavorable ion homeostasis (Lee et al. 2011). Although several salt stressrelated MAPKs have been reported, the linkage to upstream MKK or to downstream targets are not clear yet (Singh and Jwa, 2013).

An ABA-dependent $\mathrm{Ca}^{2+}$-dependent protein kinases (CDPKs), OsCPK21, have been cloned and the OsCPK21-ox transgenic rice exhibited higher salt stress tolerance than wild-type plant with enhanced expression of the ABA and salt-stress inducible genes such as OsNAC6 and Rab21 (Asano et al. 2011). An SNF1-related protein kinase (SnRK) 
functions in salt stress tolerance as well. In rice, ten members of SnRK2 family have been shown to be activated by hyperosmotic stress through phosphorylation (Kobayashi et al. 2004). Among them SAPK4 seems to play a role in the salt stress tolerance. SAPK4-ox transgenic rice revealed an improved salt tolerance with a reduced $\mathrm{Na}^{+}$accumulation in the cytosol. The vacuolar $\mathrm{Na}^{+} / \mathrm{H}^{+}$antiporter gene, OsNHX1 is less expressed in the transgenic plants, indicating the reduced $\mathrm{Na}^{+}$accumulation due to cellular $\mathrm{Na}^{+}$exclusion rather than vacuolar sequestration of the ion (Diedhiou et al. 2008).

Transcriptional regulatory network of ABA-dependent TFs (Figure 2) is recently reviewed (Todaka et al., 2012). Promoter regions of ABA-inducible genes have conserved cis-acting element, ABRE, where bZIP-type TFs bind (Yamaguchi-Shinozaki and Shinozaki 2006; Todaka et al. 2012). A T-DNA insertion mutant of salt stress inducible bZIP TF, OsABF2, increased sensitivity to salt stresses compared to control plant indicating that $O s A B F 2$ is a positive regulator of salt stress (Hossain et al. 2010). OsABF2 binds to ABRE and its N-terminal region transactivated a downstream reporter gene in yeast. Overexpression of ABAdependent stress inducible OsbZIP23 enhanced tolerance to salt and drought stresses (Xiang et al. 2008). On the other hand, overexpression of salt and ABA responsive OsABI5, another bZIP-type TF gene showed high sensitivity to salt stress, whereas transgenic rice plants expressing antisense $O s A B I 5$ showed increased salt stress tolerance. The OsABI5 protein is localized in the nucleus and binds to a G-box element (Zou et al. 2008). These opposing functions displayed by bZIP TFs, are still unclear. Microarray analysis combined with expressed sequence tag analysis of rice 89 OsbZIP genes revealed that no single gene was activated by only salt stress although several genes were activated by drought stress together (Nijhawan et al. 2008). This result may indicate that stress inducible OsbZIPs are mostly related to osmotic stress signaling via ABA.

MYB TFs containing a highly conserved DNA-binding MYB domain of 52 amino acids are also involved in the regulation of salt stress response via ABA-dependent pathway. Overexpression of a stress inducible OsMYB3R-2 improved salt stress tolerance along with cold and drought stress tolerance in Arabidopsis, with increased expression of DREB2A, COR15 $a$ and RCI2A (Dai et al. 2007). Transgenic rice overexpressing OsMYB2 also showed an enhanced salinity stress tolerance along with drought and cold stress tolerance without compromising the growth rate as compared with control (Yang et al. 2012). In the transgenic rice some putative downstream genes such as OsLEA3, OsRab16A and OsDREB2A were up regulated suggesting that OsMYB2 encodes a stress-responsive MYB TF that may act as a master switch in the stress tolerance.

NAC-type TFs also regulate some salt-responsive genes through ABA-dependent manner. They were isolated initially from Arabidopsis by yeast one hybrid screening as TFs that regulate expression of a salt-inducible ERD1 (Tran et al. 2004). High salinity stress induces several NAC genes in rice as well. Overexpression of salt stress inducible SNAC1 ( $\mathrm{Hu}$ et al. 2006) and OsNAC6 showed improved tolerance to high salinity stress although growth retardation and low yield were exhibited in OsNAC6-ox under the non-stress condition (Nakashima et al. 2007). Recently, it was shown that OsHDAC1 encoding a histone deacetylase epigenetically represses OsNAC6 expression, so the root growth retardation of OsNAC6 overexpressor is similar to the phenotype of OsHDAC1 knock-out (Chung et al. 2009). OsNAC5, another salt inducible NAC TF, binds to the NAC recognition core sequence (CACG) of OsLEA3 promoter and the transgenic overexpressor of OsNAC5 also showed improved salt tolerance (Takasaki et al. 2010). The OsNAC5 overexpression also correlated positively with accumulation of compatible solutes such as proline and soluble sugars (Song et al. 2011).

Zinc finger TFs were first recognized in Xenopus TFIIIA as a repeated zinc-binding motif containing conserved cysteine and histidine ligands (Miller et al. 1985). From rice, salt stress-responsive OSISAP1-ox conferred tolerance to salt, cold and dehydration stress in transgenic tobacco (Mukhopadhyay et al. 2004). TFIIIA-type ZFP252$o x$ rice also showed enhanced salt and drought tolerance with the elevated level of stress defense genes, as compared with ZFP252 antisense and non-transgenic plants (Xu et al. 2008). Huang et al. (2009) have isolated DST (drought and salt tolerance) gene, which negatively regulates stomatal closure and directs modulation of genes related to $\mathrm{H}_{2} \mathrm{O}_{2}$ homeostasis. DST mutant increases stomatal closure and reduces stomatal density, thus resulting in enhanced salt and drought tolerance in rice. Another salt responsive zinc finger protein gene ZFP179-ox leads to increased salt stress tolerance with increased level of free proline and soluble sugars in transgenic rice (Sun et al. 2010). An increased level of expression of a number of stress-related genes, including OsDREB2A, OsP5CS, OsProT, and OsLEA3 was observed in the transgenic rice. Recently, a salt inducible OsTZF1, a CCCH-type zinc finger protein, has been shown to bind to U-rich regions in the $3^{\prime}$ untranslated region of mRNAs (Jan et al. 2013) and overexpression of OsTZF1 showed improved tolerance to salt and drought stresses, OsTZF1 was implicated to play a role in RNA metabolism of stress-responsive genes.

WRKY TFs are also involved in stress response. Overexpression of OsWRKY13 reduced salt stress tolerance via antagonistic inhibition of SNAC1 in rice indicating that OsWRKY13 is a negative regulator of salt stress response (Qiu et al. 2008). Similarly, OsWRKY45-2 suppressing lines showed increased salt stress tolerance with reduced ABA sensitivity (Tao et al. 2011). A salt-inducible AP2/ERF type TF gene, OsERF922-ox rice shows decreased tolerance to 
salt stress with an increased $\mathrm{Na}^{+} / \mathrm{K}^{+}$ratio in the shoots (Liu et al. 2012). Apart from TFs many other downstream genes are involved in salt tolerance in rice. Hoshida et al. (2000) examined the increased photorespiration effect on the salt tolerance by overexpressing chloroplastic glutamine synthetase (GS2) gene from rice. GS2-ox rice showed increased salt stress tolerance retaining more than $90 \%$ activity of photosystem II in comparison to complete loss of photosystem II in control plant. Overexpression of a salt stress inducible JAZ protein gene, OsTIFY11a, resulted in increased salt and dehydration stress tolerance in rice, yet the function of the protein is not clear (Ye et al. 2009). OsSKIPa (Ski-interacting protein) expression is induced by various abiotic stresses and phytohormone treatments. Overexpression of $O s S K I P a$, also exhibited significantly improved growth performance in the salt and drought resistance with increased transcript levels of many stressrelated genes, such as $S N A C 1$ and rice homologs of $C B F 2$, $P P 2 C$ and $R D 22$ (Hou et al. 2009).

Recently, it has been known that microRNAs (miRNAs) play a key role in the regulation of gene expression at the post-transcriptional level. Under salt-stressed condition, expression of two microRNAs, osa-MIR396c and osaMIR393, decreased in ABA-dependent manner and overexpression of both miRNAs resulted to a reduced salt stress tolerance, which is lower than the wild-type plants (Gao et al. 2010, 2011). This suggests that these miRNAs are have some role in the salt stress tolerance, although the molecular mechanism is not clear yet.

In barley HVA1 encodes a late embryogenesis abundant (LEA) protein, which is thought as a molecular chaperon. Expression of $H V A 1$ gene led to significantly increased salt and drought tolerance in transgenic rice (Xu et al. 1996). A rice LEA gene, OsLEA3-2, was also overexpressed in rice as well as in yeast. When tested to salt stress, these transgenic organisms showed enhanced growth performance supporting the idea that LEA proteins play important role in the protection of plants under stressed conditions (Duan and Cai 2012). OsLEA3-2 was shown to protect lactate dehydrogenase from aggregation on dessication in vitro.

\section{Salt stress tolerance via ABA-independent pathway}

There are several salt stress inducible genes which are ABA-independent. These include genes for DREB1 and DREB2 TFs, some kinases, spingolipid biosynthesis enzymes, and ROS-producing/scavenging enzymes. CBF/ DREB-type genes first identified from Arabidopsis encode AP2/ERF domains that bind to a cis-acting element, DRE/CRT with a core sequence A/GCCGAC (YamaguchiShinozaki and Shinozaki 2005; Todaka et al. 2012). Rice genome contains at least fourteen DREB-type genes, among which OsDREB1A, OsDREB1F and OsDREB2A are induced by salt stress and their overexpression displayed strong abiotic stress tolerance. Transgenic Arabidopsis or rice overexpressing OsDREB1A, OsDREB1F and OsDREB2A showed improved salinity tolerance (Dubouzet et al. 2003; Wang et al. 2008; Mallikarjuna et al. 2011). Microarray analysis revealed the target stress-inducible genes of OsDREB1A and OsDREB2A encoded proteins thought to function in stress tolerance in the plants, which is similar with the target genes of DREB1 and DREB2 proteins in Arabidopsis (Sakuma et al. 2006, Jeon and Kim 2013). DRE-containing promoter region of OsDhn1 is activated by OsDREB1A and OsDREB1D (Lee et al. 2013). These observations showed that the DREB/CBF TFs are conserved in rice and Arabidopsis and DREB-type genes are useful for improvement of salt stress tolerance in transgenic rice.

ABA-independent kinases are also involved in salt stress tolerance. Overexpression of a CDPK, OsCDPK7 enhanced salt stress tolerance in transgenic rice and the extent of tolerance correlated well with the level of OsCDPK7 expression (Saijo et al. 2000). It was found that knockout plants of OsGSK1, a negative regulator gene of brassinosteroid signaling, showed enhanced tolerance to salt as well as other stresses suggesting that BR plays important role for stress tolerance (Koh et al. 2007). OsCPK12, a member of CDPK family, negatively regulates the expression of OsrbohI while it positively regulates ROS detoxification by controlling the expression of OsAPX 2 and OsAPX 8 under high salinity condition. The accumulation of $\mathrm{H}_{2} \mathrm{O}_{2}$ in OsCPK12-ox plants during salt stress was less than that in WT plants, whereas in oscpk12 and OsCPK12 RNAi plants the accumulation was more (Asano et al. 2012). This shows that OsCPK12 confers salt stress tolerance by repressing ROS accumulation rather than by affecting ABA mediated salt stress signaling.

ABA-independent ROS scavenging system is also involved in salt stress tolerance. A salt responsive malic enzyme gene in rice, $N A D P-M E$, was ectopically expressed in Arabidopsis which resulted in enhanced salt stress tolerance probably due to the increased reducing power of ROS (Liu et al. 2007). A mitochondrial superoxide dismutase gene $M n-S O D$ from Saccharomyces cerevisiae was expressed in rice chloroplast. The transgenic rice plants failed to show salt tolerance but decrease of SOD activities was slower than those of wild type at high salinity condition (Tanaka et al. 1999). Recently, katE encoding catalase from $E$. coli was transformed into rice which subsequently showed higher salt stress tolerance than the wild type with enhanced level (1.5 to 2.5 fold) of the catalase activity. Alternative oxidase (AOX) is an inner mitochondrial membrane protein that functions as terminal oxidase in the alternative (cyanide resistant) pathway, and AOX serves as oxidation stress reliever from environmental stresses, particularly salt and dehydration stress (Purvis 1997; Cournac et al. 2002). An AOX gene in rice OsIM1 was identified as salt responsive gene by using differential display method 
indicating the role of AOX pathway under salt stress (Kong et al. 2003). This implicates the importance of ROS scavenging system in the plant salt stress tolerance (Motohashi et al. 2010). Salt stress supportive genes described in this section is reported in supplemental information (Additional file 1: Table S1).

\section{Signaling molecules regulating salt stress in rice}

Under salinity stress conditions, diverse signaling molecules such as phospholipids, hormones and calcium ions $\left(\mathrm{Ca}^{2+}\right)$ regulate stress signaling pathways for maintaining an osmotic adjustment or homeostasis and regulating plant growth and development. Plant hormonal regulations and $\mathrm{Ca}^{2+}$ dependent modification of enzymatic activities are coordinately or independently integrated into the stress signaling pathways. In this section, we reviewed the recent advances in molecular mechanisms of how these signaling molecules are concerted to cytosolic and nuclear events for maintaining ionic homeostasis and salt stress tolerance in plants.

\section{Phospholipids and $\mathrm{Ca}^{2+}$ ions}

As signaling molecules, phospholipids including IP3 (Inositol triphosphate) DAG (Diacylglycerol) and PA (phosphatidic acid) seem to play an important structural roles during stress responses in inducing cytosolic $\mathrm{Ca}^{2+}$ spiking. Although the precise roles of phospholipid-based signaling in plants are still underexplored, some recent evidences have revealed their possible involvement in salt stress tolerance (Zhu 2002). Under stress conditions, PA and IP3 levels were rapidly increased in rice, Arabidopsis and tobacco (Zhu 2002; Darwish et al. 2009). Furthermore, several studies have shown that IP3 and its biosynthetic related genes rapidly increased in response to hyperosmotic stress and stress hormone ABA treatment (Drobak and Watkins 2000; DeWald et al. 2001). The formation of the phospholipid-based signaling molecules is mainly regulated by phospholipase $\mathrm{C}$ and $\mathrm{D}$ (PLC/ PLD). IP3 act as strong elicitors in mobilizing cytosolic $\mathrm{Ca}^{2+}$ levels in plants (Zhu 2002). This implies the activation of phospholipid formations for salt stressinduced cytosolic $\mathrm{Ca}^{2+}$ spiking possibly by membrane anchored salt signaling sensor proteins.

It has been well established that high salt stress rapidly leads to cytosolic $\mathrm{Ca}^{2+}$ spiking. This event spontaneously initiates the stress signaling pathways for stress tolerance via stimulating various $\mathrm{Ca}^{2+}$ binding proteins including CBL-CIPKs, CDPKs and calmodulins (Mahajan et al. 2008; Kader and Lindberg 2010). Direct evidences of the essential role of $\mathrm{Ca}^{2+}$ spiking in salt tolerance are provided by identification of Arabidopsis sos3 (Salt Overlay Sensitive3) mutants which are oversensitive to salt stress (Mahajan et al. 2008). The SOS3 encodes an EF-hand type calcineurin B-like protein (CBL) and functioned in sensing the cytosolic $\mathrm{Ca}^{2+}$ concentration by direct binding to $\mathrm{Ca}^{2+}$. Indeed, the loss-of-function sos3-1 mutation reduced its $\mathrm{Ca}^{2+}$ binding capacity, indicating that $\mathrm{Ca}^{2+}$ sensing by SOS3 is an essential mechanism for salt tolerance in plant (Sanchez-Barrena et al. 2004, 2005). The $\mathrm{Ca}^{2+}$ bound CBL proteins directly activate their interacting CIPK (CBL-interacting protein kinase) proteins. As a SOS3 interacting CIPK, SOS2 (Salt Overlay Sensitive2) was identified, and the activation of kinase activity of SOS2 by SOS3 was in a $\mathrm{Ca}^{2+}$ dependent manner (Halfter et al. 2000; Liu et al. 2000). Also, SOS2 interacts and activates vacuolar $\mathrm{N}^{+} / \mathrm{H}^{+}$and $\mathrm{H}^{+} / \mathrm{Ca}^{2+}$ antiporters and $\mathrm{V}$ ATPase independently of SOS3 leading to sequestration of excess $\mathrm{Na}^{+}$ion into vacuoles and maintain cytosolic $\mathrm{Ca}^{2+}$ level (Qiu et al. 2004; Ji et al. 2013). SOS pathway is conserved in rice and a $\mathrm{Na}^{+} / \mathrm{H}^{+}$antiporter, OsSOS1, was shown that OsSOS1 in the plasma membrane of yeast (Saccharomyces cerevisiae) cells reduced total $\mathrm{Na}^{+}$content in the cell. Other SOS2 and SOS3 homologs in rice were also identified as OsCIPK24 and OsCBL4, respectively (Atienza et al. 2007). Xiang et al. (2007) surveyed 30 putaitive CIPK genes from rice genome and found many of them showed stress responsive expression. Among those, they showed that OsCIPK15-ox transgenic rice have significantly improved tolerance to salt stress. These suggest that $\mathrm{Ca}^{2+}$ spiking by salt stress triggers the SOS3-SOS2 mediated salt stress signaling pathways. Further, these demonstrate that the high degree of functional conservation of $\mathrm{Ca}^{2+}$-mediated sodium ion homeostasis is well evolved in monocot and dicot plants. More detailed studies on the precise roles of rice SOS pathways will be necessary to extend our understanding in the molecular mechanisms of maintaining an osmotic adjustment or homeostasis. These efforts will be very helpful for developing biotechnological tools to increase osmotic and salt tolerances of crop plants.

\section{Abscisic acid (ABA)}

Plant stress hormone ABA has long been considered as an essential phytohormone for regulating various plant developmental processes as well as the adaptive responses to broad range of abiotic stresses (Zhu 2002, Hadiarto and Tran 2011). Indeed, the endogenous level of ABA and its biosynthetic genes in plant is rapidly increased by abiotic stresses including drought and salt stress. The elevated ABA hormone aids plant to acclimate under lower water availability by closing guard cells and accumulating numerous proteins for osmotic adjustment. Interestingly, the expression of many ABA biosynthetic genes seems to be regulated by a stress-induced $\mathrm{Ca}^{2+}$-dependent phosphorylation and its signaling pathways in rice ( $\mathrm{Du}$ et al. 2010; Saeng-ngam et al. 2012). For example, overexpression of drought-responsive OsDSM2 (Drought-hypersensitive mutant2) and OsCam1-1 genes led to accumulation of ABA and tolerance to salt stress in rice. OsDSM2 and OsCam1-1 
genes encode an ABA biosynthetic $\beta$-carotene hydrolase and a $\mathrm{Ca}^{2+}$-binding calmodulin, respectively ( $\mathrm{Du}$ et al. 2010; Saeng-ngam et al. 2012). These results suggest that stress-activated $\mathrm{Ca}^{2+}$ spiking could provide the positive feedback loop for ABA biosynthesis, and this event might be critical for stress tolerance in rice.

\section{Jasmonate (JA)}

JA including Methyl Jasmonate (MeJA) and its free-acid form, JA, is an important signaling molecule for diverse developmental processes and defense responses (Kazan and Manners 2012). Several studies have investigated biological relevancies of JA signaling in salt stress in rice. Interestingly, higher endogenous JA contents were observed in salt-tolerant cultivar rice than in salt-sensitive cultivar (Kang et al. 2005). In addition, MeJA level was increased by high salt stress in rice (Moons et al. 1997), supposing that high accumulation of JA in rice could be an effective protection against salt stress. Consistently, exogenous JA treatment dramatically reduced the $\mathrm{Na}^{+}$ ions in salt-tolerant cultivar rice (Kang et al. 2005).

Recent findings showed some evidences of crosstalk between $\mathrm{ABA}$ and Jasmonate (JA) in regulating salt stress (Shinozaki and Yamaguchi-Shinozaki 2007). JA is involved in development and plant defense responses through modulating JAZ (Jasmonate ZIM-domain) transcription factors. Interestingly, MYC2 transcription factors are commonly used for regulating gene expression of JA, ABA and salt stress. JA induces proteolysis of JAZ which functions in direct repressing MYC2, thereby enabling MYC2 transcription factors to activate the downstream target gene expressions (Kazan and Manners 2012). This suggests that JA plays important roles in ABA-dependent regulation of salt stress responsive genes. Several rice JAZ proteins such as OsTIFY1, 6, 9, 10 and 11 have been identified as saltinducible genes (Ye et al. 2009). However, the antagonistic roles of JA in ABA-mediated regulations of salt-stress related gene expressions have been also reported in rice root. JA treatment effectively reduced the ABA-mediated up-regulation of OsLEAs in rice root. Furthermore, JAinducible genes were not stimulated in the presence of JA and ABA (Moons et al. 1997). Taken together, this implies the involvement of different regulation mechanisms in JA and ABA-mediated responses to salt stress.

\section{Brassinosteroids (BRs)}

Plant steroid hormone BRs play essential roles in diverse plant developmental processes and stress tolerances (Vriet et al. 2012). Recently, many studies have demonstrated the positive roles of BR applications or endogenous BR contents in salt and drought stress in plant (Koh et al. 2007; Manavalan et al. 2012). BRs positively regulate salt stress responses in rice. A T-DNA inserted loss-of-function rice gsk1 mutant, an orthologous gene of a BR negative regulator, BIN2, showed an increased tolerance to salt stress compared to wild type rice (Koh et al. 2007). Furthermore, exogenous BR application could remove the salinity-induced inhibition of seed germination and seedling growth in rice. Consistently, increasing endogenous sterol contents in rice by RNAi-mediated disruption of the rice SQS (Squalene synthase) gene led to decreasing stomata density and increasing drought stress tolerance (Manavalan et al. 2012). These results describe the role of BRs in tolerance to salt and drought stress. Nonetheless, the molecular mechanisms for BR-mediated salt stress tolerance are still unclear. Some possible molecular mechanisms linked BRs with salt stress acclimation were recently demonstrated. BRs might enable plant to resist salt stress condition by reducing stomatal conductance and ER stress signaling (Che et al. 2010; Kim et al. 2012). BR signaling pathways reduced the stomata density by suppressing the BIN2 triggered inactivation of YDA-mediated stomata development signaling cascades (Kim et al. 2012), indicating that higher BR activity could decrease water loss under drought and salt stress conditions. Another possibility of BR-mediated salt stress tolerance was reported (Che et al. 2010). RIP (Regulated intermembrane proteolysis) of missfolding proteins occurred in ER by diverse stress conditions is well conserved mechanisms in eukaryotes. Two RIP related bZIP transcription factors are tightly linked with BR signaling pathways and this link is required for acclimation to numerous stresses (Che et al. 2010), suggesting the prominent roles of BRs in salt stress tolerances via ER stress signaling pathways.

\section{Genomics of osmoprotectants}

Severe osmotic stresses, salinity, drought, and cold, cause detrimental changes in cellular components. Accumulation of certain organic solutes (known as osmoprotectants) is a common metabolic adaptation found in diverse plant species. The osmoprotectants have been definitely proven to be among the most important factors to protect plant cells from dehydration and salinity (Rontein et al. 2002; Yamaguchi-Shinozaki 2002). The organic solutes protect plants from abiotic stress by osmotic adjustment, detoxification of reactive oxygen species (ROS) and stabilization of the quaternary structure of proteins (Bohnert and Jensen 1996). Transgenic plants overexpressing the genes participating in the synthesis or accumulation of osmoprotectants that function for osmotic adjustment, such as proline (Kishor et al. 1995), glycinebetaine (Holmström et al. 2000) or other osmolytes show increased salt tolerance. The most important plant osmoprotectants are proline, glycine betaine, trehalose and myo-inositol. An important feature of osmoprotectants is that their beneficial effects are generally not species-specific, so that alien osmoprotectants can be engineered into plants and protect their new host. 


\section{Proline}

Proline as an amino acid is essential for primary metabolism in plants during salt and drought stresses, showing a molecular chaperone role due to its stabilizing action either as a buffer to maintain the $\mathrm{pH}$ of the cytosolic redox status of the cell (Verbruggen and Hermans 2008; Kido et al. 2013) or as antioxidant through its involvement in the scavenging of free highly reactive radicals (Smirnoff and Cumbes 1989) or acting as a singlet oxygen quencher (Bhalu and Mohanty 2002). In higher plants, proline biosynthesis may proceed either via glutamate, by successive reductions catalyzed by pyrroline-5-carboxylate synthase (P5CS) and pyrroline-5-carboxylate reductase (P5CR) or by ornithine pathway and ornithine d-aminotransferase (OAT), representing generally the first activated osmoprotectant after stress perception (Savouré 1995; Parida et al. 2008).

Proline accumulation in transgenic rice plants with P5CS cDNA was reported and proved stress-induced overproduction of the P5CS enzyme under salinity stress (Zhu et al. 1998; Lee et al. 2012). A cDNA clone encoding P5CS was later isolated from rice and characterized. The expression of P5CS and the accumulation of proline in salt tolerant cultivar are much higher than in salt sensitive lines (Igarashi et al. 1997). When P5CS gene was overexpressed in the transgenic tobacco plants, an increased production of proline coupled with salinity tolerance were noted (Kishor et al. 1995). Thus, P5CS may not be the rate-limiting step in proline accumulation (Delauney and Verma 1993).

\section{Glycine betaine}

Betaines are amino acid derivatives in which the nitrogen atom is fully methylated such as that of quaternary ammonium compounds. Among the many quaternary ammonium compounds known in plants, glycine betaine (GB) occurs most abundantly in response to dehydration stress (Yang et al. 2003) where it reduces lipid peroxidation, thereby helps in maintaining the osmotic status of the cell to ameliorate the abiotic stress effect (Chinnusamy et al. 2005). In higher plants, glycine betaine is synthesized in the chloroplast from serine via choline by the action of choline monooxygenase (CMO) and betaine aldehyde dehydrogenase (BADH) enzymes (Ashraf and Foolad 2007).

Genes involved in osmoprotectant biosynthesis are upregulated under salt stress, and the concentrations of accumulated osmoprotectants correlates with osmotic stress tolerance (Chen and Murata 2002; Zhu 2002). Choline dehydrogenase gene $(\operatorname{cod} A)$ from Arthrobacter globiformis aids in improving the salinity tolerance in rice (Vinocur and Altman 2005).

Tolerant genotypes normally accumulate more glycine betaine than sensitive genotypes in response to stress. This relationship, however, is not universal. The osmolyte that plays a major role in osmotic adjustment is species dependent. Some plant species such as rice (Oryza sativa), mustard (Brassica spp.), Arabidopsis (Arabidopsis thaliana) and tobacco (Nicotiana tabacum) naturally do not produce glycine betaine under stress or non-stress conditions (Rhodes and Hanson 1993). In these species, transgenic plants with overexpressing glycine betaine synthesizing genes exhibited abundant production of glycine betaine, which leads plants to tolerate stresses, including salinity stress (Rhodes and Hanson 1993). The limitation in production of glycine betaine in high quantities in transgenic plants is reportedly due to either low availability of substrate choline or reduced transport of choline into the chloroplast where glycine betaine is naturally synthesized (Huang et al. 2000). Thus, to engineer plants for overproduction of osmolytes such as glycine betaine, other factors such as substrate availability and metabolic flux must also be considered.

In rice indica plant (cv. IR36), deficiency of glycine betaine has been attributed to the absence of the two enzymes, choline monooxygenase and betaine aldehyde, in the biosynthetic pathway (Rathinasabapathi et al. 1993). However, the enzymatically active BADH is detectable in Japonica variety of rice (cv. Nipponbare) (Nakamura et al. 1997). This apparent discrepancy is yet subject for further investigation. Exogenous foliar application of glycine betaine to Oryza sativa (Harinasut et al. 1996) resulted in improved growth of plants under salinity stress condition. Further, a decrease in $\mathrm{Na}^{+}$and an increase in $\mathrm{K}^{+}$concentrations in shoots were observed in GB-treated plants under salinity. This indicates the possible role of glycine betaine in signal transduction and ion homeostasis as well.

\section{Trehalose}

Trehalose is a non-reducing disaccharide in which two glucose molecules are joined together by a glycosidic (1-1) bond. In plants, the synthesis of this sugar occurs normally by the formation of the trehalose-6-phosphate (T6P) from the UDP-glucose and glucose-6-phosphate, a reaction catalyzed by the trehalose 6-phosphate synthase (TPS). Afterwards the T6P is dephosphorylated by the trehalose-6-phosphate phosphatase (TPP) resulting in the formation of free trehalose (Wingler 2002). It has been shown that trehalose can protect proteins and cellular membranes from denaturation caused by a variety of stress conditions, including desiccation (Elbein et al. 2003).

Trehalose overproduction has considerable potential for improving abiotic stress tolerance in rice transgenic plants. Increased trehalose accumulation showed higher level of tolerance to salt, drought, and low-temperature stresses, as compared with the nontransformed controls (Garg et al. 2002). Trehalose may ameliorate salinity stress through stabilization of the plasma membranes, since it decreased the rate of ion leakage and the rate of lipid peroxidation of 
the root cells, and increased the ratio of $\mathrm{K}^{+} / \mathrm{Na}^{+}$ions in the leaves of maize seedlings (Zeid 2009).

\section{Myo-inositol}

Inositol is a cyclohexanehexol, a cyclic carbohydrate with six hydroxyl groups, one on each carbon ring. Among the nine types of existing steroisomers, myo-inositol is the most abundant in the nature, being also important for the biosynthesis of a wide variety of compounds including inositol phosphates, glycosylphosphatidylinositols, phosphatidylinositides, inositol esters, and ethers in plants (Murthy 2006). Myoinositol serves as a substrate for the formation of galactinol, the galactosyl-donor that plays a key role in the formation of raffinose family oligosaccharides (RFOs, raffinose, stachyose, verbascose) from sucrose. RFOs accumulate in plants under different stress conditions (Peters et al. 2007). In the case of the halophyte Mesembryanthemum crystallinum (common ice plant) - that possesses a remarkable tolerance against drought, high salinity, and cold stress inositol is methylated to D-ononitol and subsequently epimerized to Dpinitol. This plant accumulates a large amount of these inositol derivatives during the stress (Vernon et al. 1993). Due to the potential of myo-inositol, some transgenic plants expressing this substance have been generated, mainly using MIPS enzyme or inositol derived enzymes. Isolation of the PINO1 gene (also known as PcINO1, encoding an 1-myo-inositol 1-phosphate synthase) from the wild halophytic rice relative Porteresia coarctata and transformation in tobacco has been reported (Majee et al. 2004). This gene conferred tobacco plants tolerance to 200-300 $\mathrm{mM} \mathrm{NaCl}$ keeping up $40-80 \%$ of the photosynthetic competence with concomitant increased inositol production, which is significantly better than the unstressed control. Additionally, PINO1 transgenics showed in vitro salttolerance, complementing in planta functional expression of this gene.

\section{Genomic overview of transporters in rice salt response}

Various channels, carriers and pumps are working for the ion homeostasis in the cell and salt stress causes ions unbalance (Figure 3). In rice, 1,200 transporter proteins have been annotated from the genome sequence, among which $84 \%$ are active transporters (Nagata et al. 2008). Here we briefly reviewed ion transporters involved in the salt tolerance.

\section{$\mathrm{Na}^{+} / \mathrm{H}^{+}$antiporters}

The importance of $\mathrm{Na}^{+}$transporters for $\mathrm{Na}^{+}$tolerance in plant was first known in sugar beets (Blumwald and Poole, 1987). Activity and function of $\mathrm{Na}^{+} / \mathrm{H}^{+}$antiporters, major $\mathrm{Na}^{+}$transporters in plants, have been studied in various plants including rice and Arabidopsis. In Arabidopsis, the plasma membrane $\mathrm{Na}^{+} / \mathrm{H}^{+}$antiporter (SOS1) regulates sodium efflux in roots and the long-distance transport of sodium from roots to shoots (Wu et al. 1996). A functional homologue of SOS1 in rice, OsSOS1, had been isolated and a T-DNA insertion mutant of OSSOS1 exhibited a salt sensitivity. It has been reported that SOS1 proteins contain self-inhibitory domains at their carboxy termini and the truncation of this inhibitory domain in OsSOS1 resulted in a much greater $\mathrm{Na}^{+}$ transport activity with enhanced salt tolerance in yeast cells (Atienza et al. 2007). In rice genome 13 antiporters are retrieved through in silico analysis, nine of which are $\mathrm{Na}^{+} / \mathrm{H}^{+}$antiporters and 4 are $\mathrm{K}^{+} / \mathrm{H}^{+}$antiporters, whereas 35 antiporters were retrieved in Arabidopsis with 29 being $\mathrm{Na}^{+} / \mathrm{H}^{+}$antiporters and $6 \mathrm{~K}^{+} / \mathrm{H}^{+}$ antiporters.

In rice, 4 vacuolar $\mathrm{Na}^{+} / \mathrm{H}^{+}$antiporters $(O s N H X 1-4)$ and one endosomal $\mathrm{Na}^{+} / \mathrm{H}^{+}$antiporter (OsNHX5) have been reported (Bassil et al. 2012). OsNHX3 was showed to be phosphorylated at S471 in the C-terminus, a residue that is conserved in other vacuolar isoforms, suggesting that S471 is important for the activation of the antiporters. Overexpression of OsNHX1 in rice and in maize improved salt tolerance by enhancing the compartmentalization of $\mathrm{Na}^{+}$into the vacuoles (Chen et al. 2007). $\mathrm{Ca}^{2+} / \mathrm{H}^{+}$antiporter (CAX) is a pump which helps intracellular $\mathrm{Ca}^{2+}$ ion homeostasis (Figure 3). From rice genome sequence four CAX genes (OsCAX1a, OsCAX1b, OsCAX2 and OsCAX3) and $O s C A X 1 c$, a pseudogene of $C A X 1$, were retrived. Expression of all rice CAX genes except OsCAX2 showed $\mathrm{Ca}^{2+}$ tolerance in yeast (Kamiya et al. 2004, 2005). It is noticeable that in a salt tolerant rice cultivar $\mathrm{Fl}$, the expression of a CAX-type exchanger was down-regulated compared to that of a salt sensitive cultivar RI, suggesting that the down-regulation of the CAX exchanger may be related to salt tolerance (Senadheera et al. 2009). However it is yet unknown whether or not CAX genes play direct role in the salt stress tolerance in rice.

\section{$\mathrm{Na}^{+} / \mathrm{K}^{+}$symporter}

HKT is a $\mathrm{Na}^{+} / \mathrm{K}^{+}$symporter or $\mathrm{Na}^{+}$uniporter present in the plasma membrane of plant cells. Rice genome has seven $H K T$ transporter genes and two pseudogenes whereas Arabidopsis has 16 HKT transporter genes (Garciadeblas et al. 2003, Platten et al. 2006). Horie et al. (2007) reported that oshkt2;1 mutant showed significant growth defect when a moderate amount of $\mathrm{Na}^{+}$exists in $\mathrm{K}^{+}$- deficient condition. These results indicated that the OsHKT2;1-dependent $\mathrm{Na}^{+}$ influx in $\mathrm{K}^{+}$- deficient roots is regulated to prevent $\mathrm{Na}^{+}$toxicity due to mass flow of $\mathrm{Na}^{+}$through OsHKT2;1 (Figure 2.) A QTL, SKC1, from a salt tolerant variety which maintained $\mathrm{K}^{+}$homeostasis under salt stress was mapped (Ren et al., 2005). Isolation of $S K C 1$ gene, which encodes HKTtype $\mathrm{Na}^{+}$-transporter suggested the role of $S K C 1$ in $\mathrm{K}^{+} / \mathrm{Na}^{+}$ homeostasis under salt stress. 


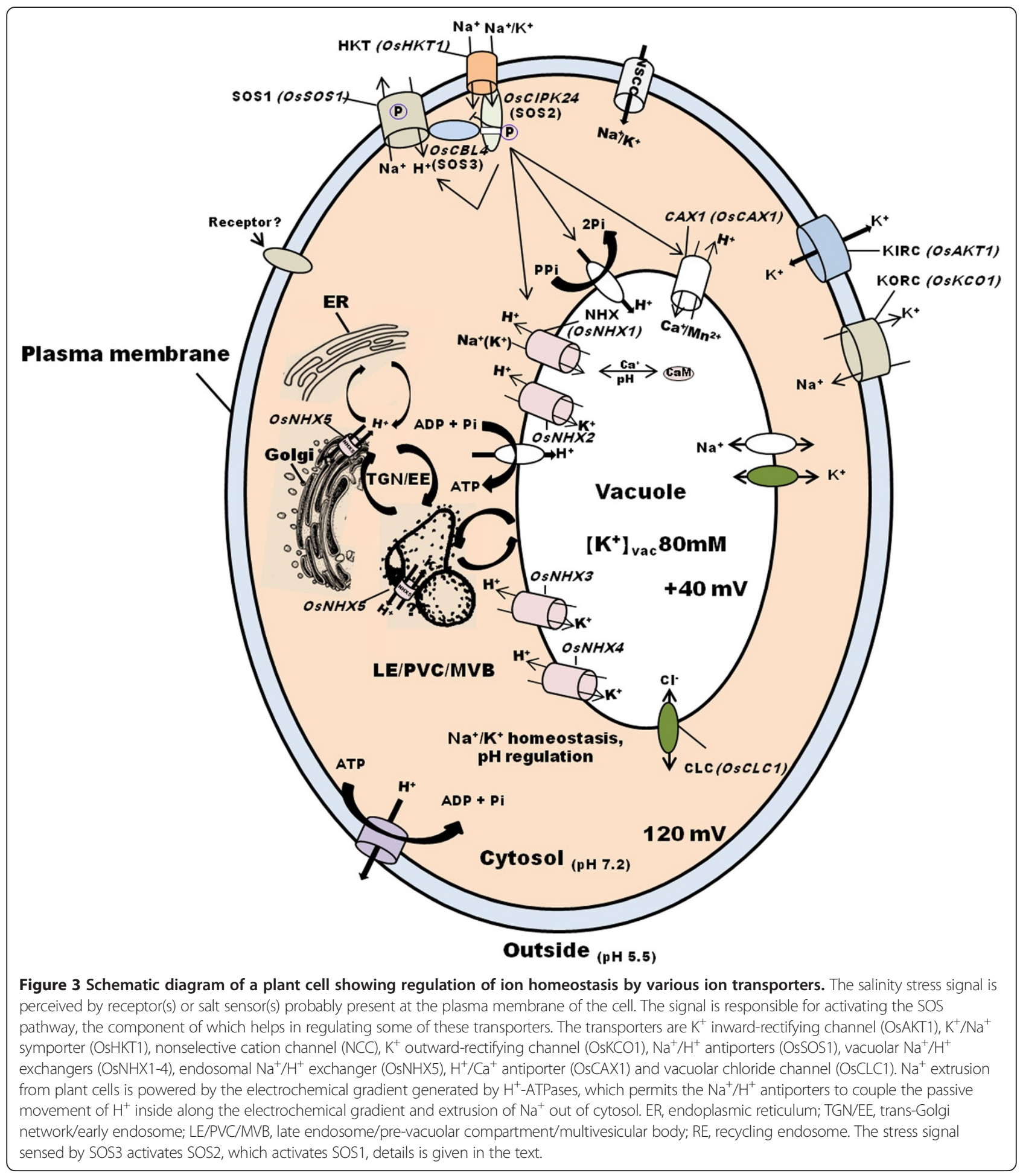

$\mathrm{H}^{+}$-ATPase are primary active transporters. An electrochemical gradient generated by $\mathrm{H}^{+}$-ATPase helps in $\mathrm{Na}^{+}$ extrusion out of the cytosol. In silico analysis of rice genome revealed that $11 \mathrm{H}^{+}$-ATPases are present in the vacuole, plasma membrane and Trans Golgi Network (TGN). In Arabidopsis, mutant lacking vacuolar $\mathrm{V}-\mathrm{H}^{+}$-ATPase subunits showed a reduced tonoplast V-ATPase activity, but did not show sensitivity to high salinity (Krebs et al. 2010). However, a knockout of an endosomal (EE/TGN) $V$ $H^{+}$-ATPase mutant showed increased salt sensitivity, indicating the importance of the endosomal system for the salt tolerance. In rice, expression of $H^{+}$-ATPase gene, OSA3, 
under salt stress was greatly induced in a salt-tolerant mutant M-20, but not in a salt-sensitive variety $77-170$, suggesting an active role of $O S A 3$ in relation with salt stress tolerance. However, there is no direct evidence that any of $\mathrm{H}^{+}$-ATPases in rice are involved in the salt stress tolerance.

\section{Channel protein}

Several channel proteins are also involved in salt stress response in rice. Nonselective cation channels (NCCs) are proposed as an entry gate of $\mathrm{Na}^{+}$into the plant cell. It was hypothesized that NCCs play a significant role in root $\mathrm{Na}^{+}$ uptake because of similarity between $\mathrm{Na}^{+}$current and $\mathrm{Ca}^{2+}$ inhibition of radioactive $\mathrm{Na}^{+}$influx (Demidchik et al. 2007). However, the exact conductance and proportion of this pathway may vary. Chloride ions are also important for salt stress response and chloride channel (CLC) although other channels are also involved in chloride transport. In silico analysis revealed that rice genome has 9 chloride channel $(C L C)$ genes. Those channel proteins are present in vacuole, Golgi body and chloroplast. A salt stress inducible OsCLC1 was identified from rice and the OsCLC1 was shown to operate as anion channels in one system, but $\mathrm{H}^{+} / \mathrm{Cl}^{-}$antiporter in another (Nakamura et al. 2006). Although there is no direct evidence that OsCLC genes have roles in the salt stress tolerance, a comparison study revealed that there was a genotype-dependent differences in expression of OsCLC1. Under salt stress, saltsensitive IR29 had repressed expression of OsCLC1, while salt-tolerant Pokkali showed induction particularly in roots, suggesting that the level of OsCLC1 expression is correlated to the salt tolerance (Diedhiou and Golldack 2006). Inward-rectifying $\mathrm{K}^{+}$channels (KIRC) mediates the influx of $\mathrm{K}^{+}$on the plasma membrane and it selectively accumulates $\mathrm{K}^{+}$over $\mathrm{Na}^{+}$upon the plasma membrane hyperpolarization (Muller-Rober et al. 1995; Golldack et al. 2003). In rice genome, 15 are retrieved in silico compared to 12 in Arabidopsis. A few KIRC-encoding genes $(A K T)$ have been functionally characterized. Salt stress inhibited OsAKT1 gene expression and the inward $\mathrm{K}^{+}$influx was significantly decreased in root protoplasts by salt stress, suggesting that OsAKT1 is a dominant salt-sensitive $\mathrm{K}^{+}$uptake channel (Fuchs et al. 2005). Recently, it was shown that overexpression of a bHLH-type transcription factor gene OrbHLHOO1 in transgenic rice increased the salt tolerance of transgenic rice with increased level of OsAKT1 gene expression (Chen et al. 2013). More detailed studies on the precise roles of rice transporter genes will be helpful in understanding the molecular mechanisms of maintaining an osmotic adjustment or homeostasis and these efforts will be helpful for developing salt tolerant rice plants.

\section{Conclusion}

Availability of high quality rice genome sequence fast tracked the progress made in functional genomics of salinity tolerance in rice. This aids in the discovery of several genes that could be deployed for use in breeding for rice salt tolerance. The complex mechanism underlying salt tolerance as well as the complex nature of salt stress itself and the wide range of plant responses make the trait unexplainable. Even so, several evidences showed that members of protein families involved in signal transduction, osmoregulation, ion transportation and protection from oxidative damage are critical in governing high salt tolerance (Figure 2). Various multiple signaling pathways can be activated during exposure to stress, leading to similar responses to different stimuli which suggest the overlap in gene expression between environmental stresses. Rice exhibits cellular ion homeostasis and enormous genetic variability in its sensitivity to salt stress. The indica varieties Pokkali and Nonabokra have higher endogenous ABA level during osmotic shock and are classified as highly salt tolerant ecotypes. To maximize the productivity of rice under saline soils there is an urgent need to look for sources of genetic variation that can be used for developing new cultivars with greater yield potential and stability over seasons and ecogeographic locations. Identification of molecular markers associated with salt stress tolerance genes or QTL conferring tolerance to high salinity has been demonstrated. Significant breakthroughs have been made on the mechanism and control of salinity stress tolerance in rice, but large gaps about our understanding in this field remained to be explored. Thus, further investigations are needed to sufficiently explain the underlying mechanisms of protection of rice under salt stress condition. Identification of the role of different component providing salt stress and the cross talks between these components will be a future challenge to disentangle the complete genome network of rice providing salinity tolerance. An emerging scope to identify novel cis-acting elements and elements acting in tandem may possibly lead to unraveling the complex web pattern for salinity signaling. Apparently, development of plants with improved tolerance to salt remained a big challenge despite the significant progress in genomics of salt tolerance in rice.

\section{Additional file}

Additional file 1: Table S1. List of salt stress supportive genes

described in this paper.

Competing interests

The authors declare that they have no competing interests.

\section{Authors' contributions}

All of the authors contributed equally to the drafting and revising the manuscript. All authors read and approved the final manuscript.

\section{Acknowledgements}

The work in KK lab was supported by Science \& Engineering Research Board (SB/FT/LS-312/2012), Department of Science \& Technology, India. The work in 
SRK lab was supported by a grant from the Rural Development Administration (No. PJ008197) Republic of Korea. The work in YGC lab was supported by a grant from the Rural Development Administration (No. PJ008529) and the iPET, Ministry for Food, Agriculture, Forestry and Fisheries, Republic of Korea.

\section{Author details}

'Department of Biological Sciences, Birla Institute of Technology \& Science, K. K. Birla Goa Campus, Goa 403726, India. ${ }^{2}$ Department of Life Science, Sogang University, Seoul 121-742, Korea. ${ }^{3}$ Department of Life Science, Pohang University of Science \& Technology, Pohang 790-784, Korea. ${ }^{4}$ Department of Crop Science, Chungbuk National University, Cheongju 361-763, Korea.

\section{Received: 6 May 2013 Accepted: 29 August 2013}

\section{Published: 28 October 2013}

\section{References}

Agrawal GK, Rakwa R, Iwahashi H (2002) Isolation of novel rice (Oryza sativa L) multiple stress responsive MAP kinase gene, OSMSRMK2, whose mRNA accumulates rapidly in response to environmental cues. Biochem Biophys Res Commun 294:1009-1016

Agrawal GK, Agrawal SK, Shibato J, Iwahashi H, Rakwal R (2003) Novel rice MAP kinases OSMSRMK3 and OSWJUMK1 involved in encountering diverse environmental stresses and developmental regulation. Biochem Biophys Res Commun 300:775-783

Asano T, Hakata M, Nakamura H, Aoki N, Komatsu S, Ichikawa H, Hirochika H, Ohsugi $R$ (2011) Functional characterisation of OsCPK21, a calcium-dependent protein kinase that confers salt tolerance in rice. Plant Mol Biol 75:179-191

Asano T, Hayashi N, Kobayashi M, Aoki N, Miyao A, Mitsuhara I, Ichikawa H, Komatsu S, Hirochika H, Kikuchi S, Ohsugi R (2012) A rice calcium-dependent protein kinase OsCPK12 oppositely modulates salt-stress tolerance and blast disease resistance. Plant J 69:26-36

Ashraf M, Foolad MR (2007) Roles of glycine betaine and proline in improving plant abiotic stress resistance. Environ Exp Bot 59:206-216

Atienza JM, Jiang X, Garciadeblas B, Mendoza I, Zhu JK, Pardo JM, Quintero FJ (2007) Conservation of the salt overly sensitive pathway in rice. Plant Physiol 143:1001-1012

Bassil E, Coku A, Blumwald E (2012) Cellular ion homeostasis: emerging roles of intracellular $\mathrm{NHX} \mathrm{Na}^{+} / \mathrm{H}^{+}$antiporters in plant growth and development. J Exp Bot 63:5727-5740

Bhalu B, Mohanty P (2002) Molecular mechanisms of quenching of reactive oxygen species by proline under stress in plants. Curr Sci 82:525-532

Blumwald E, Poole R (1987) Salt-tolerance in suspension cultures of sugar beet. Induction of $\mathrm{Na}^{+} / \mathrm{H}^{+}$-antiport activity at the tonoplast by growth in salt. Plant Physiol 83:884-887

Bohnert HJ, Jensen RG (1996) Strategies for engineering water-stress tolerance in plants. Trends Biotech 14:89-97

Che P, Bussell JD, Zhou W, Estavillo GM, Pogson BJ, Smith SM (2010) Signaling from the endoplasmic reticulum activates brassinosteroid signaling and promotes acclimation to stress in Arabidopsis. Sci Signal 3:ra69

Chen TH, Murata N (2002) Enhancement of tolerance of abiotic stress by metabolic engineering of betaines and other compatible solutes. Curr Opin Plant Biol 5:250-257

Chen M, Chen QJ, Niu XJ, Zhang R, Li HQ, Xu CY, et al. (2007) Expression of OsNHX1 gene in maize confers salt tolerance and promotes plant growth in the field. Plant Soil Environ 53:490-498

Chen Y, Lia F, Maa Y, Chong K, XU Y (2013) Overexpression of OrbHLH001, a putative helix-loop-helix transcription factor, causes increased expression of AKT1 and maintains ionic balance under salt stress in rice. J Plant Physiol 170:93-100

Chinnusamy V, Jagendorf A, Zhu JK (2005) Understanding and improving salt tolerance in plants. Crop Sci 45:437-448

Chinnusamy V, Zhu J, Zhu JK (2006) Gene regulation during cold acclimation in plants. Physiol Plant 126:52-61

Chung PJ, Kim YS, Jeong JS, Park SH, Nahm BH, Kim JK (2009) The histone deacetylase OsHDAC1 epigenetically regulates the OsNAC6 gene that controls seedling root growth in rice. Plant J 59:764-776

Cournac L, Latouche G, Cerovic Z, Redding K, Ravenel J, Peltier G (2002) In vivo interactions between photosynthesis, mitorespiration, and chlororespiration in Chlamydomonas reinhardtii. Plant Physiol 129:1921-1928

Dai X, Xu Y, Ma Q, Xu W, Wang T, Xue Y, Chong K (2007) Overexpression of an R1R2R3 MYB gene, OSMYB3R-2, increases tolerance to freezing, drought, and salt stress in transgenic Arabidopsis. Plant Physiol 143:1739-1751
Darwish E, Testerink C, Khalil M, El-Shihy O, Munnik T (2009) Phospholipid signaling responses in salt-stressed rice leaves. Plant cell physiol 50:986-997

Delauney AJ, Verma DPS (1993) Proline biosynthesis and osmoregulation in plants. Plant J 4:215-223

Demidchik V, Maathuis FJ (2007) Physiological roles of nonselective cation channels in plants: from salt stress to signalling and development. New Phytol 175:387-404

DeWald DB, Torabinejad J, Jones CA, Shope JC, Cangelosi AR, Thompson JE, Prestwich GD, Hama H (2001) Rapid accumulation of phosphatidylinositol 4,5-bisphosphate and inositol 1,4,5-trisphosphate correlates with calcium mobilization in salt-stressed Arabidopsis. Plant physiol 126:759-769

Diedhiou CJ, Golldack D (2006) Salt-dependent regulation of chloride channel transcripts in rice. Plant Sci 170:793-800

Diedhiou CJ, Popova OV, Dietz KJ, Golldack D (2008) The SNF1-type serinethreonine protein kinase SAPK4 regulates stress-responsive gene expression in rice. BMC Plant Biol 8:49

Drobak BK, Watkins PA $(2000)$ Inositol $(1,4,5)$ trisphosphate production in plant cells: an early response to salinity and hyperosmotic stress. Biochem Biophys Res Commun 481:240-244

Du H, Wang N, Cui F, Li X, Xiao J, Xiong L (2010) Characterization of the betacarotene hydroxylase gene DSM2 conferring drought and oxidative stress resistance by increasing xanthophylls and abscisic acid synthesis in rice. Plant Physiol 154:1304-1318

Duan J, Cai W (2012) OsLEA3-2, an abiotic stress induced gene of rice plays a key role in salt and drought tolerance. PLoS One 79:e45117

Dubouzet JG, Sakuma Y, Ito Y, Kasuga M, Dubouzet EG, Miura S, Seki M, Shinozaki K, Yamaguchi-Shinozaki K (2003) OsDREB genes in rice, Oryza sativa L. encode transcription activators that function in drought, high salt and coldresponsive gene expression. Plant J 33:751-763

Elbein AD, Pan YT, Pastuszak I, Carroll D (2003) New insights on trehalose: a multifunctional molecule. Glycobiology 13:17R-27

FAO (2009) High level expert forum - how to feed the world in 2050. Economic and social development department. Food and Agricultural Organization of the United Nations, Rome

Fu SF, Chou WC, Huang DD, Huang HJ (2002) Transcriptional regulation of a rice mitogen-activated protein kinase gene, OSMAPK4, in response to environmental stresses. Plant Cell Physiol 43:958-963

Fuchs I, Stolzle S, Ivashikina N, Hedrich R (2005) Rice $K^{+}$uptake channel OsAKT1 is sensitive to salt stress. Planta 221:212-221

Gao P, Bai X, Yang L, Lv D, Li Y, Cai H, Ji W, Guo D, Zhu Y (2010) Overexpression of osa-MIR396c decreases salt and alkali stress tolerance. Planta 231:991-1001

Gao P, Bai X, Yang L, Lv D, Pan X, Li Y, Cai H, Ji W, Chen Q, Zhu Y (2011) osaMIR393: a salinity and alkaline stress-related microRNA gene. Mol Biol Rep $38: 237-242$

Garciadeblas B, Senn ME, Banuelos MA, Rodriguez-Navarro A (2003) Sodium transport and HKT transporters: the rice model. Plant J 34:788-801

Garg AK, Kim JK, Owens TG, Ranwala AP, Choi YD, Kochian LV, Wu RJ (2002) Trehalose accumulation in rice plants confers high tolerance levels to different abiotic stresses. Proc Natl Acad Sci USA 99:15898-15903

Golldack D, Quigley F, Michalowski CB, Kamasani UR, Bohnert HJ (2003) Salinity stress tolerant and sensitive rice (Oryza sativa L.) regulate AKT1-type potassium channel transcripts differently. Plant Mol Biol 51:71-81

Hadiarto T, Tran LS (2011) Progress studies of drought-responsive genes in rice. Plant Cell Rep 30:297-310

Halfter U, Ishitani M, Zhu JK (2000) The Arabidopsis SOS2 protein kinase physically interacts with and is activated by the calcium-binding protein SOS3. Proc Natl Acad Sci USA 97:3735-3740

Harinasut P, Tsutsui K, Takabe T, Nomura M, Kishitani S (1996) Exogenous glycine betaine accumulation and increased salt tolerance in rice seedlings. Biosci Biotechnol Biochem 60:366-368

Holmström KO, Somersalo S, Mandal A, Palva TE, Welin B (2000) Improved tolerance to salinity and low temperature in transgenic tobacco producing glycine betaine. J Exp Bot 51:177-185

Horie T, Costa A, Kim TH, Han MJ, Horie R, Leung HY, Miyao A, Hirochika H, An G, Schroeder JI (2007) Rice OsHKT2;1 transporter mediates large $\mathrm{Na}^{+}$influx component into $\mathrm{K}^{+}$-starved roots for growth. EMBO J 26:3003-3014

Hoshida H, Tanaka Y, Hibino T, Hayashi Y, Tanaka A, Takabe T, Takabe T (2000) Enhanced tolerance to salt stress in transgenic rice that overexpresses chloroplast glutamine synthetase. Plant Mol Biol 43:103-111 
Hossain MA, Cho Jl, Han M, Ahn CH, Jeon JS, An G, Park PB (2010) The ABRE binding bZIP transcription factor OSABF2 is a positive regulator of abiotic stress and ABA signaling in rice. J Plant Physiol 167:1512-1520

Hou X, Xie K, Yao J, Qi Z, Xiong L (2009) A homolog of human ski-interacting protein in rice positively regulates cell viability and stress tolerance. Proc Natl Acad Sci USA 106:6410-6415

Hu H, Dai M, Yao J, Xiao B, Li X, Zhang Q, et al. (2006) Overexpressing a NAM, ATAF, and CUC (NAC) transcription factor enhances drought resistance and salt tolerance in rice. Proc Natl Acad Sci USA 103:12987-12992

Huang J, Hirji R, Adam L, Rozwadowski KL, Hammerlindl JK, Keller WA, Selvaraj G (2000) Genetic engineering of glycinebetaine production toward enhancing stress tolerance in plants: metabolic limitations. Plant Physiol 122:747-756

Huang XY, Chao DY, Gao JP, Zhu MZ, Shi M, Lin HX (2009) A previously unknown zinc finger protein, DST, regulates drought and salt tolerance in rice via stomatal aperture control. Genes Dev 23:1805-1817

Igarashi Y, Yoshiba Y, Sanada Y, Yamaguchi-Shinozaki K, Wada K, Shinozaki K (1997) Characterization of the gene for $\Delta 1$-pyrroline-5-carboxylate synthatase and correlation between the expression of the gene and salt tolerance in Oryza sativa. Plant Mol Biol 33:857-865

Jan A, Maruyama K, Todaka DS, Abo M, Yoshimura E, Shinozaki K, Nakashima K, Shinozaki KY (2013) OsTZF1, a CCCH-tandem zinc finger protein, confers delayed senescence and stress tolerance in rice by regulating stress-related genes. Plant Physiol 161:1202-1216

Jeon J, Kim J (2013) Cold stress signaling networks in Arabidopsis. J Plant Biol 56:69-76

Jeong MJ, Lee SK, Kim BG, Kwon TR, Cho WS, Park YT, Lee JO, Kwon HB, Byun MO, Park SC (2006) A rice (Oryza sativa L.) MAP kinase gene, OsMAPK44, is involved in response to abiotic stresses. Plant Cell Tiss Organ Cult 85:151-160

Ji H, Pardo JM, Batelli G, Oosten MJV, Bressan RA, Li X (2013) The salt overly sensitive (SOS) pathway: established and emerging roles. Mol Plant $6: 275-286$

Kader MA, Lindberg S (2010) Cytosolic calcium and pH signaling in plants under salinity stress. Plant Signal Behav 5:233-238

Kamiya T, Maeshima M (2004) Residues in internal repeats of the rice cation/ $\mathrm{H}^{+}$ exchanger are involved in the transport and selection of cations. J Biol Chem 279:812-819

Kamiya T, Akahori T, Ashikari M, Maesshima M (2005) Expression of the vacuolar $\mathrm{Ca}^{2+} / \mathrm{H}^{+}$exchanger, OsCAX1a, in rice: cell and age specificity of expression and enhancement by $\mathrm{Ca}^{2+}$. Plant Cell Physiol 47:96-106

Kang D, Seo Y, Lee JD, Ishii R, Kim KU, Shin DH, Park SK, Lee I (2005) Jasmonic acid differentially affects growth, ion uptake and abscisic acid concentration in salt tolerant and salt sensitive rice cultivars. J Agro Crop Sci 191:273-282

Kazan K, Manners JM (2012) JAZ repressors and the orchestration of phytohormone crosstalk. Trends Plant Sci 17:22-31

Kido EA, Neto JRF, Silva RL, Belarmino LC, Neto JPB, Soares-Cavalcanti NM, Pandolfi V, Silva MD, Nepomuceno AL, Benko-Iseppon M (2013) Expression dynamics and genome distribution of osmoprotectants in soybean: identifying important components to face abiotic stress. BMC Bioinformatics 14:S7

Kim JA, Agrawal GK, Rakwal R, Han KS, Kim KN, Yun CH, Heu S, Park SY, Lee YH, Jwa NS (2003) Molecular cloning and mRNA expression analysis of a novel rice (Oryza sativa L.) MAPK kinase kinase, OsEDR1, an ortholog of Arabidopsis AtEDR1, reveal its role in defense/stress signalling pathways and development. Biochem Biophys Res Commun 300:868-876

Kim TW, Michniewicz M, Bergmann DC, Wang ZY (2012) Brassinosteroid regulates stomatal development by GSK3-mediated inhibition of a MAPK pathway. Nature 482:419-422

Kishor PBK, Hong Z, Miao G, Hu C, Verma DPS (1995) Overexpression of $\Delta 1$ pyrroline-5-carboxylate synthetase increases proline production and confers osmotolerance in transgenic plants. Plant Physiol 108:1387-1394

Kobayashi Y, Yamamoto S, Minami H, Kagaya Y, Hattori T (2004) Differential activation of the rice sucrose nonfermenting 1-related protein kinase 2 family by hyperosmotic stress and abscisic acid. Plant Cell 16:1163-1177

Koh S, Lee SC, Kim MK, Koh JH, Lee S, An G, Choe S, Kim SR (2007) T-DNA tagged knockout mutation of rice OSGSK1, an orthologue of Arabidopsis BIN2, with enhanced tolerance to various abiotic stresses. Plant Mol Biol 65:453-466

Kong J, Gong JM, Zhang JG, Zhang JS, Chen SY (2003) A new AOX homologous gene OsIM1 from rice (Oryza sativa L.) with an alternative splicing mechanism under salt stress. Theor Appl Genet 107:326-331

Krebs M, Beyhl D, Gorlich E, Al-Rasheid KAS, Marten I, Stierhof YD, Hedrich R, Schumacher K (2010) Arabidopsis V-ATPase activity at the tonoplast is required for efficient nutrient storage but not for sodium accumulation. Proc Natl Acad Sci USA 107:3251-3256

Kumari S, Sabharwal VP, Khushwaha HR, Sopory SK, Singla-Pareek SL, Pareek A (2009) Transcriptome map of seedling stage specific salinity response indicate a specific set of genes as candidate for saline tolerance in Oryza sativa L. Funct Integr Genomics 9:109-123

Lee SK, Kim BG, Kwon TR, Jeong MJ, Park SR, Lee JW, Byun MO, Kwon HB, Matthews BF, Hong CB, Park SC (2011) Overexpression of the mitogenactivated protein kinase gene OsMAPK33 enhances sensitivity to salt stress in rice (Oryza sativa L.). J Biosci 36:139-151

Lee HJ, Abdula SE, Ryu HJ, Jee MG, Jang DW, Kang KK, Cho YG (2012) BrCIPK1 encoding CBL-interacting protein kinase 1 from Brassica rapa regulates abiotic stress responses by increasing proline biosynthesis. 10th International Symposium on Rice Functional Genomics, Chiang Mai, Thailand. OG-11

Lee SC, Kim SH, Kim SR (2013) Drought inducible OsDhn1 promoter is activated by OsDREB1A and OsDREB1D. J Plant Biol 56:115-121

Liu J, Ishitani M, Halfter U, Kim CS, Zhu JK (2000) The Arabidopsis thaliana SOS2 gene encodes a protein kinase that is required for salt tolerance. Proc Natl Acad Sci USA 97:3730-3734

Liu S, Cheng Y, Zhang X, Guan Q, Nishiuchi S, Hase K, Takano T (2007) Expression of an NADP-malic enzyme gene in rice (Oryza sativa. L.) is induced by environmental stresses; over-expression of the gene in Arabidopsis confers salt and osmotic stress tolerance. Plant Mol Biol 64:49-58

Liu D, Chen X, Liu J, Ye J, Guo Z (2012) The rice ERF transcription factor OsERF922 negatively regulates resistance to Magnaporthe oryzae and salt tolerance. J Exp Bot 63:3899-3912

Lutts S, Kinet JM, Bouharmont J (1995) Changes in plant response to $\mathrm{NaCl}$ during development of rice (Oryza sativa L.) varieties differing in salinity resistance. J Exp Bot 46:1843-1852

Mahajan S, Pandey GK, Tuteja N (2008) Calcium and salt-stress signaling in plants: shedding light on SOS pathway. Archives Biochem Biophys 471:146-158

Majee M, Maitra S, Dastidar KG, Pattnaik S, Chatterjee A, Hait NC, Das KP, Majumder AL (2004) A novel salt-tolerant L-myo-Inositol-1-phosphate synthase from Porteresia coarctata (Roxb.) Tateoka, a halophytic wild rice. J Biol Chem 279:28539-28552

Mallikarjuna G, Mallikarjuna K, Reddy MK, Kaul T (2011) Expression of OsDREB2A transcription factor confers enhanced dehydration and salt stress tolerance in rice (Oryza sativa L.). Biotechnol Lett 33:1689-1697

Manavalan LP, Chen X, Clarke J, Salmeron J, Nguyen HT (2012) RNAi-mediated disruption of squalene synthase improves drought tolerance and yield in rice. J Exp Bot 63:163-175

Mantri N, Patade V, Penna S, Ford R, Pang E (2012) Abiotic stress responses in plants: present and future. In: Ahmad P, Prasad MNV (ed) Abiotic stress responses in plants: metabolism, productivity and sustainability. Springer, New York, pp 1-19

Miller J, McLachlan AD, Klug A (1985) Repetitive zinc-binding domains in the protein transcription factor IIIA from Xenopus oocytes. EMBO J 4:1609-1614

Moons A, Prinsen E, Bauw G, Van Montagu M (1997) Antagonistic effects of abscisic acid and jasmonates on salt stress-inducible transcripts in rice roots. Plant Cell 9:2243-2259

Motohashi T, Nagamiya K, Prodhan SH, Nakao K, Shishido T, Yamamoto Y, Moriwaki T, Hattori E, Asada M, Morishima H, Hirose S, Ozawa K, Takabe T, Takabe T, Komamine A (2010) Production of salt stress tolerant rice by overexpression of the catalase gene, katE, derived from Escherichia coli. Asia Pac J Mol Biol Biotechnol 18:37-41

Mukhopadhyay A, Vij S, Tyagi AK (2004) Overexpression of a zinc-finger protein gene from rice confers tolerance to cold, dehydration, and salt stress in transgenic tobacco. Proc Natl Acad Sci USA 101:6309-6314

Muller-Rober B, Ellenberg J, Provart N, Willmitzer L, Busch H, Becker D, Dietrich P, Hoth S, Hedrich R (1995) Cloning and electrophysiological analysis of KST1, an inward rectrifying $\mathrm{K}^{+}$channel expressed in potato guard cells. EMBO J 14:2409-2416

Munns R, Tester M (2008) Mechanisms of salinity tolerance. Annu Rev Plant Biol 59:651-681

Murthy PP (2006) Structure and Nomenclature of Inositol Phosphates, Phosphoinositides, and Glycosylphosphatidylinositols. In: Biswas BB (ed) Biology of Inositols and Phosphoinositides: Subcellular Biochemistry. Majumder, L. \& Biswas, pp 1-19

Nagata T, lizumi S, Satoh K, Kikuchi S (2008) Comparative molecular biological analysis of membrane transport genes in organisms Plant Mol Biol 66:565-585 
Nakamura T, Yokota S, Muramoto Y, Tsutsui K, Oguri Y, Fukui K, Takabe T (1997) Expression of a betaine aldehyde dehydrogenase gene in rice, a glycinebetaine nonaccumulator, and possible localization of its protein in peroxisomes. Plant J 11:1115-1120

Nakamura A, Fukuda A, Sakai S, Tanaka Y (2006) Molecular cloning, functional expression and subcellular localization of two putative vacuolar voltagegated chloride channels in rice (Oryza sativa L.). Plant Cell Physiol 47:32-42

Nakashima K, Tran LS, Van Nguyen D, Fujita M, Maruyama K, Todaka D, Ito Y, Hayashi N, Shinozaki K, Shinozaki KY (2007) Functional analysis of a NAC-type transcription factor OsNAC6 involved in abiotic and biotic stress-responsive gene expression in rice. Plant J 51:617-630

Nijhawan A, Jain M, Tyagi AK, Khurana JP (2008) Genomic survey and gene expression analysis of the basic leucine zipper transcription factor family in rice. Plant Physiol 146:333-350

Ning J, Li X, Hicks LM, Xiong L (2010) A raf-like MAPKKK gene DSM1 mediates drought resistance through reactive oxygen species scavenging in rice. Plant Physiol 152:876-890

Ouyang SQ, Liu YF, Liu P, Lei G, He SJ, Ma B, Zhang WK, Zhang JS, Chen SY (2010) Receptor-like kinase OsSIK1 improves drought and salt stress tolerance in rice (Oryza sativa) plants. Plant J 62:316-329

Parida AK, Dagaonkar VS, Phalak MS, Aurangabadkar LP (2008) Differential responses of the enzymes involved in proline biosynthesis and degradation in drought tolerant and sensitive cotton genotypes during drought stress and recovery. Acta Physiol Plant 30:619-627

Peters S, Mundree SG, Thomson JA, Farrant JM, Keller F (2007) Protection mechanisms in the resurrection plant Xerophyta viscosa (Baker): both sucrose and raffinose family oligosaccharides (RFOs) accumulate in leaves in response to water deficit. J Exp Bot 58:1947-1956

Platten JD, Cotsaftis O, et al. (2006) Nomenclature for HKT transporters, key determinants of plant salinity tolerance. Trends Plant Sci 11:372-374

Purvis AC (1997) Role of the alterantive oxidase in limiting superoxide production by plant mitochondria. Physiol Plant 100:164-170

Qiu QS, Guo Y, Quintero FJ, Pardo JM, Schumaker KS, Zhu JK (2004) Regulation of Vacuolar $\mathrm{Na}^{+} / \mathrm{H}^{+}$Exchange in Arabidopsis thaliana by the Salt-OverlySensitive (SOS) Pathway. J Biol Chem 279:207-215

Qiu D, Xiao J, Xie W, Liu H, Li X, Xiong L, Wang S (2008) Rice gene network inferred from expression profiling of plants overexpressing OsWRKY13, a positive regulator of disease resistance. Mol Plant 1:538-551

Rathinasabapathi B, Gage DA, Mackill DJ, Hanson AD (1993) Cultivated and wild rice do not accumulate glycinebetaine due to deficiencies in two biosynthetic steps. Crop Sci 33:534-538

Ren ZH, Gao JP, Li LG, Cai XL, Huang W, Chao DY, et al. (2005) A rice quantitative trait locus for salt tolerance encodes a sodium transporter. Nature Genet 37:1141-1146

Rhodes D, Hanson AD (1993) Quaternary ammonium and tertiary sulfonium compounds in higher plants. Annu Rev Plant Physiol Plant Mol Biol 44:357-384

Rontein D, Basset G, Hanson AD (2002) Metabolic engineering of osmoprotectant accumulation in plants. Metab Eng 4:49-56

Saeng-ngam S, Takpirom W, Buaboocha T, Chadchawan S (2012) The role of the OsCam1-1 salt stress sensor in ABA accumulation and salt tolerance in rice. J Plant Biol 55:198-208

Saijo Y, Hata S, Kyozuka J, Shimamoto K, Izui K (2000) Overexpression of a single $\mathrm{Ca}^{2+}$ dependent protein kinase confers both cold and salt/drought tolerance on rice plants. Plant J 23:319-327

Sakamoto A, Alia MN (1998) Metabolic engineering of rice leading to biosynthesis of glycinebetaine and tolerance to salt and cold. Plant Mol Biol 38:1011-1019

Sakuma Y, Maruyama K, Osakabe Y, Qin F, Seki M, Shinozaki K, et al. (2006) Functional analysis of an Arabidopsis transcription factor, DREB2A, involved in drought-responsive gene expression. Plant Cell 18:1292-1309

Sanchez-Barrena MJ, Martinez-Ripoll M, Zhu JK, Albert A (2004) SOS3 (salt overly sensitive 3) from Arabidopsis thaliana: expression, purification, crystallization and preliminary X-ray analysis. Acta crystallogr D Biol crystallogr 60:1272-1274

Sanchez-Barrena MJ, Martinez-Ripoll M, Zhu JK, Albert A (2005) The structure of the Arabidopsis thaliana SOS3: molecular mechanism of sensing calcium for salt stress response. J Mol Biol 345:1253-1264

Savouré A, Jaoua S, Hua XJ, Ardiles W, Van Montagu M, Verbruggen N (1995) Isolation, characterization, and chromosomal location of a gene encoding the delta 1pyrroline-5-carboxylate synthetase in Arabidopsis thaliana. FEBS Lett 372:13-19

Senadheera P, Singh R, Maathuis F (2009) Differentially expressed membrane transporters in rice roots may contribute to cultivar dependent salt tolerance. J Exp Bot 60:2553-2563
Shanker AK, Venkateswarlu B (2011) Abiotic stress in plants - mechanisms and adaptations.. InTech Publisher, Rijeka, Croatia, p 428

Shinozaki K, Yamaguchi-Shinozaki K (2007) Gene networks involved in drought stress response and tolerance. J Exp Bot 58:221-227

Singh R, Jwa NS (2013) The rice MAPKK-MAPK interactome: the biological significance of MAPK components in hormone signal transduction. Plant Cell Rep 32:923-931

Singh AK, Ansari MW, Pareek A, Singla-Pareek SL (2008) Raising salinity tolerant rice: recent progress and future perspectives. Physiol Mol Biol Plants 14:137-154

Singla-Pareek SL, Yadav SK, Pareek A, Reddy MK, Sopory SK (2008) Enhancing salt tolerance in a crop plant by overexpression of glyoxalase II. Trans Res 17:171-180

Smirnoff N, Cumbes QJ (1989) Hydroxyl radical scavenging activity of compatible solutes. Phytochem 28:1057-1060

Song SY, Chen Y, Chen J, Dai XY, Zhang WH (2011) Physiological mechanisms underlying OsNAC5-dependent tolerance of rice plants to abiotic stress. Planta 234:331-345

Sun SJ, Guo SQ, Yang X, Bao YM, Tang HJ, Sun H, Huang J, Zhang HS (2010) Functional analysis of a novel Cys2/His2-type zinc finger protein involved in salt tolerance in rice. J Exp Bot 61:2807-2818

Takasaki H, Maruyama K, Kidokoro S, Ito Y, Fujita Y, Shinozaki K, Shinozaki KY, Nakashima K (2010) The abiotic stress-responsive NAC-type transcription factor OsNAC5 regulates stress-inducible genes and stress tolerance in rice. Mol Genet Genomics 284:173-183

Tanaka Y, Hibin T, Hayashi Y, Tanaka A, Kishitani S, Takabe T, Yokota S, Takabe T (1999) Salt tolerance of transgenic rice overexpressing yeast mitochondrial Mn-SOD in chloroplasts. Plant Sci 148:131-138

Tao Z, Kou Y, Liu H, Li X, Xiao J, Wang S (2011) OsWRKY45 alleles play different roles in abscisic acid signalling and salt stress tolerance but similar roles in drought and cold tolerance in rice. J Exp Bot 62:4863-4874

Thakur P, Kumar S, Malik JA, Berger JD, Nayyar H (2010) Cold stress effects on reproductive development in grain crops: an overview. Environ Exp Bot 67:429-443

Todaka D, Nakashima K, Shinozaki K, Yamaguchi-Shinozaki K (2012) Towards understanding transcriptional regulatory networks in abiotic stress responses and tolerance in rice. Rice 5:6

Tran LSP, Nakashima K, Sakuma Y, Simpson SD, Fujita Y, Maruyama K, Fujita M, Seki M, Kazuo Shinozaki K, Shinozaki KY (2004) Isolation and functional analysis of Arabidopsis stress-Inducible NAC transcription factors that bind to a drought-responsive cis-element in the early responsive to dehydration stress 1 Promoter. Plant Cell 16:2481-2498

Uddin MI, Qi Y, Yamada S, Shibuya I, Deng XP, Kwak SS, Kaminak H, Tanak K (2008) Overexpression of a new rice vacuolar antiporter regulating protein OsARP improves salt tolerance in tobacco. Plant Cell Physiol 49:880-890

Verbruggen N, Hermans C (2008) Proline accumulation in plants: a review. Amino Acids 35:753-759

Verma D, Singla-Pareek SL, Rajgopal D, Reddy MK, Sopory SK (2007) Functional validation of a novel isoform of $\mathrm{Na}^{+} / \mathrm{H}^{+}$antiporter from Pennisetum glaucum for enhancing salinity tolerance in rice. J Biosci 32:621-628

Vernon D, Ostrem J, Bohnert H (1993) Stress perception and response in a facultative halophyte: the regulation of salinity-induced genes in Mesembryanthemum crystallinum. Plant Cell Environ 16:437-444

Vinocur B, Altman A (2005) Recent advances in engineering plant tolerance to abiotic stress: achievements and limitations. Curr Opin Biotech 16:123-132

Vriet C, Russinova E, Reuzeau C (2012) Boosting crop yields with plant steroids Plant cell 24:842-857

Wang W, Vinocur B, Altman A (2003) Plant responses to drought, salinity and extreme temperatures: towards genetic engineering for stress tolerance. Planta 218:1-14

Wang Q, Guan Y, Wu Y, Chen H, Chen F, Chu C (2008) Overexpression of a rice OSDREBTF gene increases salt, drought, and low temperature tolerance in both Arabidopsis and rice. Plant Mol Biol 67:589-602

Welsch R, Wust F, Bar C, Babili SA, Beyer P (2008) A third phytoene synthase is devoted to abiotic stress-induced abscisic acid formation in rice and defines functional diversification of phytoene synthase genes. Plant Physiol 147:367-380

Wingler A (2002) The function of trehalose biosynthesis in plants. Phytochem 60:437-440

Wu SJ, Ding L, Zhu JK (1996) SOS1, a genetic locus essential for salt tolerance and potassium acquisition. Plant Cell 8:617-627

Xiang Y, Huang Y, Xiong L (2007) Characterization of stress-responsive CIPK genes in rice for stress tolerance improvement. Plant Physiol 144:1416-1428 
Xiang Y, Tang N, Du H, Ye H, Xiong L (2008) Characterization of OsbZIP23 as a key player of the basic leucine zipper transcription factor family for conferring abscisic acid sensitivity and salinity and drought tolerance in rice. Plant Physiol 148:1938-1952

Xiong L, Yang Y (2003) Disease resistance and abiotic stress tolerance in rice are inversely modulated by an abscisic acid-inducible mitogen-activated protein kinase. Plant Cell 15:745-759

Xiong L, Zhu JK (2001) Abiotic stress signal transduction in plants: molecular and genetic perspectives. Physiol Plant 112:152-166

Xu D, Duan X, Wang B, Hong B, Ho THD, Ray Wu R (1996) Expression of a late embryogenesis abundant protein gene, hva1, from barley confers tolerance to water deficit and salt stress in transgenic rice. Plant Physiol 110:249-257

Xu DQ, Huang J, Guo SQ, Yang X, Bao YM, Tang HJ, Zhang HS (2008) Overexpression of a TFIIIA-type zinc finger protein gene ZFP252 enhances drought and salt tolerance in rice (Oryza sativa L.). FEBS Lett 582:1037-1043

Yamaguchi-Shinozaki K, Shinozaki K (2005) Organization of cis-acting regulatory elements in osmotic- and cold-stress-responsive promoters. Trends Plant Sci 10:88-94

Yamaguchi-Shinozaki K, Shinozaki K (2006) Transcriptional regulatory networks in cellular responses and tolerance to dehydration and cold stresses. Annu Rev Plant Biol 57:781-803

Yamaguchi-Shinozaki K, Kasuga M, Liu Q, Nakashima K, Sakuma Y, Abe H, Shinwari ZK, Seki M, Shinozaki K (2002) Biological mechanisms of drought stress response. JIRCAS Working Report 2002 23:1-8

Yang WJ, Rich PJ, Axtell JD, Wood KV, Bonham CC, Ejeta G, Mickelbart MV, Rhodes D (2003) Genotypic variation for glycine betaine in sorghum. Crop Sci 43:162-169

Yang A, Dai X, Zhang WH (2012) A R2R3-type MYB gene, OSMYB2, is involved in salt, cold, and dehydration tolerance in rice. J Exp Bot 63:2541-2556

Ye H, Du H, Tang N, Li X, Xiong L (2009) Identification and expression profiling analysis of TIFY family genes involved in stress and phytohormone responses in rice. Plant Mol Biol 71:291-305

Ye N, Jia L, Zhang J (2012) ABA signal in rice under stress conditions. Rice 5:1-9

Zeid IM (2009) Trehalose as osmoprotectant for maize under salinity-induced stress. Res J Agri Biol Sci 5:613-622

Zhu JK (2002) Salt and drought stress signal transduction in plants. Ann Rev Plant Biol 53:247-273

Zhu B, Su J, Chang M, Verma DPS, Fan YL, Wu R (1998) Overexpression of a 1pyrroline-5-carboxylate synthetase gene and analysis of tolerance to water and salt-stress in transgenic rice. Plant Sci 139:41-48

Zou M, Guan Y, Ren H, Zhang F, Chen F (2008) A bZIP transcription factor, OsABI5, is involved in rice fertility and stress tolerance. Plant Mol Biol 66:675-683

doi:10.1186/1939-8433-6-27

Cite this article as: Kumar et al.: Insights into genomics of salt stress response in rice. Rice 2013 6:27.

\section{Submit your manuscript to a SpringerOpen ${ }^{\odot}$ journal and benefit from:}

- Convenient online submission

- Rigorous peer review

- Immediate publication on acceptance

- Open access: articles freely available online

- High visibility within the field

- Retaining the copyright to your article

Submit your next manuscript at $>$ springeropen.com 